Jurnal Care Vol .5, No.3,Tahun 2017

\title{
EFFECTIVENESS OF METHODS FOCUS GROUP DISCUSSION (FGD) PARENTAL COMMUNICATION IN THE ROLE OF ADOLESCENT SEXUAL BEHAVIOR IN SMAN 3 KOTA CIREBON YEAR 2016
}

\author{
Elfi $^{1)}$ Yeni Fitrianingsih ${ }^{2)}$ \\ ${ }^{1,2)}$ Politeknik Kesehatan Tasikmalaya Kementerian Kesehatan RI \\ Program Studi Kebidanan Cirebon \\ e-mail: elfirosse2@gmail.com
}

\begin{abstract}
Parental communications about sex is the interaction between the parent and the teen where parents consciously seek to provide information about sex or contraception. The protectors that influence risky sexual behavior in adolescents are an individual, family, peers, school, and community/neighborbood. Parental communication is one protective factor against adolescent risky sexual behavior.Objective to determine the effectiveness of the Focus Group Discussion (FGD) in the role of parental communication on adolescent sexual behavior at SMAN 3 Cirebon in 2016. The study design used was quasiexperimental. This study used a quantitative approach to determine the effectiveness of Focus Group Discussion on the role of parental communication against adolescent sexual behavior. A qualitative approach was used to assess the role of parent communication by conducting FGDs and performing pretest and posttest on the role of parental communication and adolescent sexual behavior.Most of the role of parent communication on adolescent sexual behavior was high. There was a high-risk sexual behavior by 3.7\%. An increased role of parental communication in both groups was seen. The results of independent $t$ test were significant with a p-value of $<0.05$. Therefore, practically the FGD group showed a more effective result to enhance the role of parental communication than the counseling group.It is expected that the board of management of SMAN 3 Cirebon can include parents in improving the role of parental communication, especially for adolescent sexual behavior in any of the activities held in school such as parents' meetings.
\end{abstract}

Keywords: adolescent sexual behavior, FGD, parental communication

\begin{abstract}
ABSTRAK
Komunikasi orang tua tentang seksual adalah interaksi antara satu orang tua dan satu remaja di mana orang tua secara sadar berusaha untuk memberikan informasi tentang seksual atau kontrasepsi. Protektor yang mempengaruhi perilaku seksual berisiko pada remaja adalah individu, keluarga, teman sebaya, lingkungan sekolah dan komunitas/lingkungan sekitar. Komunikasi orang tua merupakan salah faktor protektif terhadap perilaku seksual remaja yang berisiko.Tujuan penelitian untuk mengetahui efektifitas Focus Group Discussion (FGD) dalam peranan komunikasi orang tua terhadap perilaku seksual remaja di SMAN 3 Kota Cirebon Tahun 2016. Rancangan penelitian yang digunakan adalah quasi experimental dengan pendekatan kuantitatif.Sampel terbagi menjadi dua kelompok yaitu kelompok kelompok perlakuan (FGD) 10 orang dan pada kelompok kontrol 10 orang Instrumen
\end{abstract}


berupa kuesioner yang diadopsi dari penelitian Amran AA tahun 2010. Hasil diketahui bahwa sebagian besar peranan komunikasi orangtua terhadap perilaku seksual remaja adalah tinggi. Terdapat perilaku seksual berisiko tinggi sebanyak 3,7\% dan terdapat peningkatan peranan komunikasi orangtua pada kedua kelompok. Hasil uji statistik independent t test didapatkan hasil yang signifikan $(\mathrm{p}<0,05)$, secara praktis kelompok FGD lebih efektif meningkatkan peranan komunikasi orangtua dibanding kelompok penyuluhan. Diharapkan penentu kebijakan di SMAN 3 Kota Cirebon dapat mengikutsertakan orang tua terutama dalam hal mempersiapkan remaja menjadi generasi yang sehat, berperilaku sesuai dengan norma agama pada setiap kegiatan yang diadakan disekolah seperti rapat orangtua.

Kata Kunci: FGD, Komunikasi orang tua, Perilaku seksual remaja,

\section{PENDAHULUAN}

Masa remaja merupakan proses kematangan emosional, psikososial, dan seksual, yang ditandai dengan mulai berfungsinya organ reproduksi dan segala konsekuensinya. Salah satu isu penting yang dihadapi remaja sehubungan dimulainya kematangan seksual dan berfungsinya alat reproduksi adalah terjadinya perilaku seksual yang berisiko. Isu tersebut muncul sebagai akibat informasi tentang kesehatan reproduksi yang didapat dari sumber dan cara yang tidak benar (Suzuki et al., 2006).

Remaja yang dahulu masih terjaga secara kuat oleh sistem keluarga, adat budaya serta nilai-nilai tradisional yang ada, telah mengalami pengikisan yang disebabkan oleh urbanisasi dan industrialisasi yang cepat. Hal ini diikuti pula oleh adanya revolusi media yang terbuka bagi keragaman gaya hidup dan pilihan karir. Berbagai hal tersebut mengakibatkan peningkatan kerentanan remaja terhadap berbagai macam penyakit, terutama yang berhubungan dengan kesehatan seksual dan reproduksi, termasuk ancaman yang meningkat terhadap HIV/AIDS. (Suryoputro dkk, 2006). Penelitian yang dilakukan oleh Sieving et al. (2002) mengatakan bahwa protektor yang mempengaruhi perilaku seksual berisiko pada remaja adalah individu, keluarga, teman sebaya, lingkungan sekolah dan komunitas/lingkungan sekitar. Komunikasi orang tua merupakan salah faktor protektif terhadap perilaku seksual remaja yang berisiko.

Komunikasi didefinisikan sebagai proses percakapan yang terus menerus bukan hanya sesekali dan difokuskan atas pesan apa yang disampaikan, pesan apa yang di dengar dan pesan apa yang dipahami ( Ramos \& Bouris, 2008). Sedangkan definisi komunikasi orang tua tentang seksual menurut Jaccard et al. (2002) adalah interaksi antara satu orang tua dan satu remaja di mana orang tua secara sadar 
berusaha untuk memberikan informasi tentang seksual atau kontrasepsi.Sumber komunikasi yaitu orang tua. Karakteristik orang tua (usia, tingkat pendidikan, jenis kelamin, cara berkomunikasi, keahlian, pengetahuan, kenyamanan, dan sikap terhadap pendidikan seksual) berhubungan dengan terlaksananya proses komunikasi yang efektif.

Perubahan lain yang terjadi pada masa remaja yang dapat mempengaruhi hubungan orangtua dengan remaja adalah : pubertas, perubahan di sekolah, teman sebaya, persahabatan, pacaran, dan pergaulan menuju kebebasan. Karakter remaja tersebut, sering berpengaruh terhadap pola hubungan antara anak dan orang tua. Bahkan tak jarang terjadi konflik. Beberapa remaja juga mengeluhkan cara-cara orang tua memperlakukan mereka yang otoriter, atau sikap-sikap orang tua yang terlalu kaku atau tidak memahami kepentingan remaja. Remaja sendiri juga sering dihadapkan pada dilema-dilema moral sehingga remaja merasa bingung terhadap keputusan-keputusan moral yang harus diambilnya. Walaupun di dalam keluarga mereka sudah ditanamkan nilai-nilai, tetapi remaja akan merasa bingung ketika menghadapi kenyataan, ternyata nilai-nilai tersebut sangat berbeda dengan nilai-nilai yang dihadapi bersama teman-temannya maupun di lingkungan yang berbeda. Sebaliknya, banyak orang tua maupun pendidik merasa khawatir bahwa anakanak mereka terutama remaja mengalami degradasi moral. (Nurhidayah, 2011)

Remaja membutuhkan dukungan untuk dapat memenuhi rasa ingin tahunya tersebut, namun pada kenyataannya norma dan budaya di Indonesia masih menganggap seks sebagai hal yang tabu. Remaja dianggap belum cukup umur dan tidak layak mengetahui informasi tentang seks dari orangtua ataupun sekolah, sehingga remaja lebih tertarik untuk mencari sendiri informasi mengenai seks.Sikap remaja yang lebih tertarik untuk mencari sendiri informasi mengenai seks membuat remaja rawan berperilaku negatif terkait perilaku seks pranikah. Survei Demografi dan Kesehatan Indonesia pada tahun 2002, 2007, dan 2012 menyatakan ada berbagai macam jenis perilaku seks yang dilakukan dalam berpacaran, yaitu $70 \%$ berpegangan tangan, 4,82\% berciuman, dan aktivitas saling merangsang sebanyak 13,6\%. Kemudian, sebanyak 21\% remaja laki-laki dan $2 \%$ remaja perempuan mengaku memiliki teman yang pernah melakukan hubungan seks pranikah ( Fauzy, ZF \& Indrijati,H， 2014). Didukung hasil 
penelitian yang mengatakan bahwa prilaku seksual pada remaja dapat terjadi dilingkungan masyarakat yakni penelitian Putra (2013) Hasil dari penelitian ini menunjukkan bahwa komunikasi interpersonal yang meliputi keterbukaan, empati, sikap mendukung, kesetaraan, dan sikap positif berjalan baik meskipun masih terdapat anak yang tidak terlalu terbuka kepada orangtuanya karena masih merasa takut dan malu. Orang tua juga perlu memberikan pemahaman agama dan juga pengawasan dalam penggunaan sumber media informasi melalui komunikasi interpersonal terhadap anak agar terhindar dari perilaku seks pranikah.

Kegagalan fungsi keluarga, hal ini memicu mereka untuk berperilaku bebas bahkan melanggar norma sekalipun, karena merasa tidak ada yang peduli atau mencegah hal tersebut. 2) Pengaruh media, hal tersebut menunjukkan bahwa media sangat berpengaruh terhadap perilaku seks pranikah. 3) Rendahnya pendidikan nilai-nilai agama, hal tersebut nampak dari pendapat para responden yang mengakui bahwa mereka masih belum memahami pendidikan agama yang mereka peroleh selama ini. Ini menunjukkan bahwa pendidikan agama yang mereka peroleh selama duduk di bangku sekolah sangat minim. (Salisa, 2010).

Pola komunikasi yang harus digunakan orangtua pada anak remaja adalah pola komunikasi authoritative atau pola komunikasi demokratis. Sehingga komunikasi interpersonal antara orangtua dengan anak dapat terjalin dengan baik sebagai komunikator maupun sebagai komunikan. (Fajarwati, 2011). Komunikasi yang dilakukan remaja dan orang tua biasanya berkaitan dengan masalah yang dihadapi remaja, serta menjadi tanggung jawab orang tua. Termasuk dalam berkomunikasi tentang masalah seksual, peran orang tua menjadi penting dalam memberikan wawasan yang tepat bagi berbagai pertanyaan atau rasa ingin tahu anak tentang hal itu. Sebab bila orang tua tidak memberikan penjelasan yang tepat mengenai organ-organ seks dan fungsinya kepada anak remaja maka mereka akan mencari tahu informasi diluar rumah misalnya melalui internet, film, dan teman. Tentu saja apabila anak tidak cukup mendapat bimbingan dari orang tua, maka informasi yang mereka dapatkan bisa saja disalahgunakan sehingga akhirnya mendorong dilakukannya perilaku seksual yang belum waktunya mereka lakukan seperti misalnya seks bebas yang berbuntut kehamilan di luar 
pernikahan.(Munawaroh, 2012). Peran orangtua terhadap pendidikan seks pada remaja sangat penting sekali, sebagian orangtua kurang memperhatikan dan masih ada orang tua yang menganggap berbicara masalah seks itu tabu, karena tidak pantas dibicarakan secara terbuka. Dalam hasil penelitiannya mengatakan bahwa terdapat hubungan penyuluhan kesehatan terhadap pengetahuan tentang peran orang tua dalam memberikan pendidikan seks pada remaja (Prihartanti, Z dkk. 2013) Bagaimanapun juga peranan dan dukungan orangtua sangat dibutuhkan oleh remaja, apapun hasil dan akibatnya.

Menurut data Survey Kesehatan Reproduksi Remaja pada tahun 2007 melaporkan bahwa terdapat 1\% wanita pernah melakukan hubungan seksual dan laki-laki cenderung $6 \%$ serta belum berusia 15-24. Data tersebut menyebutkan sebanyak 5.912 wanita di umur 15-19 tahun secara nasional pernah melakukan hubungan seksual. Sedangkan pria di usia yang sama berjumlah 6.578, atau 3,7 persen pernah melakukan hubungan seks. Namun yang mengejutkan kasus hubungan seks pranikah ini justru terjadi di pedesaan.
Masalah seksual pada remaja hakekatnya bersumber pada perubahan organobiologik akibat pematangan organorgan reproduksi yang seringkali tidak diketahui oleh remaja. Biran Affandi (1991) menyebutkan bahwa salah satu masalah utama yang dihadapi oleh remaja kini adalah makin meningkatnya kesenjangan antara usia reproduksi yang datang lebih dini dan usia menikah yang relatif lebih tinggi. Di lain pihak, perubahan kehidupan masyarakat dari tradisional menjadi modern membawa pergesearn nilai-nilai, yang pada gilirannya mempengaruhi perilaku seksual para remaja (Soejati, SZ, 2001). Menurut sumber data dari Badan Pemberdayaan Perempuan dan KB Provinsi Jawa Barat tahun 2009 bahwa 28\% remaja di Jawa Barat telah melakukan hubungan seksual pranikah. Hasil penelitian yang disampaikan BKKBN Online di lima Kota Besar di Jawa Barat diwakili kota Tasikmalaya dan Cirebon mengatakan bahwa 17\% remaja Tasik mengaku sudah melakukan hubungan seksual pranikah dan $6,7 \%$ remaja Cirebon mengaku menganut seks bebas. Berdasarkan hasil penelitian yang dilakukan oleh Safitri (2011) bahwa 45,3\% remaja di salah satu SMU Kota Cirebon pernah melakukan perilaku seksual berat. 
METODE PENELITIAN

Penelitian ini merupakan quasi experimental dengan menggunakan pendekatan kuantitatif. Pendekatan kualitatif digunakan untuk menilai peranan komunikasi orangtua dengan cara melakukan FGD dan pengambilan data didukung dengan melakukan pretest dan posttest mengenai peranan komunikasi orangtua dan perilaku seksual remaja. Responden dibagi menjadi dua kelompok yaitu kelompok yaitu pada kelompok perlakuan (FGD) adalah 10 dan pada kelompok kontrol 10 orang.Instrumen yang digunakan adalah kuesioner yang digunakan dalam penelitian ini diadopsi dari penelitian Amran AA tahun 2010. Analisa data dengan menggunakan independen $t$ test untuk mengetahui perbedaan selisih rerata pretest dan postest pada kelompok intervensi dan kontrol, pada tingkat kemaknaan $\mathrm{p}<0,05$.

\section{HASIL}

\section{Analisis Par T Test}

Tabel 1. Efektifitas FGD dalam Peranan Komunikasi Orang Tua Terhadap Perilaku Seksual Remaja di SMAN 3 Kota Cirebon

\begin{tabular}{llccccc}
\hline & & Mean & Sd & p & $\begin{array}{c}\text { Perubahan } \\
\text { skor }\end{array}$ & CI 95\% \\
\hline Perlakuan & Pretest & 60.30 & 4.83 & 0.001 & 14.70 & $14.21-15.18$ \\
& Postest & 75.00 & 5.05 & & & \\
\multirow{2}{*}{ Kontrol } & Pretest & 58.80 & 3.22 & 0.001 & 2.00 & $1.66-2.33$ \\
& Postest & 60.80 & 3.15 & & & \\
\hline
\end{tabular}

Berdasarkan Tabel 1 didapatkan hasil mean pretest skor komunikasi orang tua pada kelompok perlakuan sebesar 60.30 dengan standar deviasi 4.83. setelah dilakukan treatmen terdapat peningkatan hasil rerata nya postest menjadi 75.00 dengan standar deviasi 5.05. secara praktis setelah dilakukan treatmen (rerata postestpretest) terdapat kenaikan rerata skor komunikasi orang tua sebesar 14.70. dari hasil uji statistic tersebut hasilnya signifkan $\mathrm{p}<0.05$. Sedangkan kelompok kontrol didapatkan hasil mean pretest skor komunikasi orang tua pada kelompok kontrol sebesar 58,80 dengan standar deviasi 3,22 setelah dilakukan treatmen terdapat peningkatan hasil rerata nya postest menjadi 60,80 dengan standar deviasi 3,15 secara praktis setelah dilakukan treatmen (rerata postest-pretest) terdapat kenaikan rerata skor komunikas orang tua sebesar 2,00 dari hasil uji statistic 
tersebut hasilnya signifkan perlakuan peningkatannya lebih tinggi $\mathrm{p}<0.05$.Walaupun pada kedua kelompok dibandingan kelompok kontrol. terdapat peningkatan, namun kelompok

\section{Analisis Independent $T$ Test}

Tabel 2. Selisih Rerata Pretest dan Postest Pada Kelompok Perlakuan Dan Kontrol Efektifitas FGD dalam Peranan Komunikasi Orangtua Terhadap Perilaku Seksual Remaja di SMAN 3 Kota Cirebon 2016

\begin{tabular}{lccccc}
\hline & Mean & Sd & $\mathrm{p}$ & $\begin{array}{c}\text { Perubahan } \\
\text { skor }\end{array}$ & CI 95\% \\
\hline $\begin{array}{l}\text { Perlakuan } \\
\text { Kontrol }\end{array}$ & 14,70 & 0,67 & 0,001 & 12,70 & $12,15-13,24$ \\
\hline
\end{tabular}

Berdasarkan Tabel 2 dapat dilihat hasil uji statistic independent t test didapatkan hasil nya secara statistic signifikan $(\mathrm{p}<0,05)$, secara praktis kelompok perlakuan hasilnya peningkatan lebih besar 12,70.

\section{PEMBAHASAN}

Berdasarkan hasil pada Tabel 1, bahwa pada kedua kelompok terdapat peningkatan, namun kelompok FGD peningkatannya lebih tinggi dibandingan kelompok kontrol. Hal ini sesuai dengan hasil penelitian yang dilakukan oleh Ginting, MDR (2014) menunjukkan hasil bahwa FGD efektif meningkatkan perubahan perilaku pada hampir seluruh resiko perokok untuk mengontrol keingian merokok. Hasil penelitian yang senada menurut Amanda(2014) menunjukkan bahwa pendidikan kesehatan dengan metode FGD lebih efektif dalam meningkatkan pengetahuan warga binaan mengenai infeksi menular seksual dengan nilai $\quad$ v value $=$ 0,016 $(\mathrm{P}<0,05)$ daripada pendidikan kesehatan dengan media visual dengan $p$ value sebesar 0,281.

Masa remaja mengalami proses kematangan emosional, psikososial, dan seksual, yang ditandai dengan mulai berfungsinya organ reproduksi dan segala konsekuensinya. Salah satu isu penting yang dihadapi remaja sehubungan dimulainya kematangan seksual dan berfungsinya alat reproduksi adalah terjadinya perilaku seksual yang berisiko. Isu tersebut muncul sebagai akibat informasi tentang kesehatan reproduksi yang didapat dari sumber dan cara yang tidak benar (Suzuki et al., 2006).

Pembentukan rasa percaya diri remaja awal tidak bisa lepas dari peran, turut campur orang tua. Dalam hal ini keluarga merupakan sebuah lingkungan yang paling 
awal untuk membantu remaja mendapat rasa aman, diterima sehingga akan berdampak positif dalam perkembangan jiwa remaja. Keluarga merupakan tempat atau lingkungan yang dekat dengan kehidupan remaja, sehingga remaja mampu berupaya untuk terbuka dalam menghadapi masalah.

Komunikasi antara orang tua dan anak akan mampu membantu orang tua dan remaja, dalam menghadapi problema masa remaja. Kurangnya pengetahuan yang dimiliki orang tua atau terhambat oleh sopan santun atau rasa malu menjadi salah satu penghambat komunikasi.. Kesenjangan yang sering berkembang antara remaja awal dan orang tua menghalangi remaja bertanya mengenai perubahan yang terjadi pada tubuhnya berkaitan dengan organ reproduksinya. Perubahan yang terjadi pada remaja dapat mempengaruhi kepercayaan dirinya, karena kurangnya informasi yang diterima. Remaja cenderung tidak percaya diri dalam menghadapi berbagai perubahan tersebut. Orang tua lebih terbuka dalam memberikan pengarahan, informasi, dan memberikan kesempatan pada anak agar mau bercerita tentang keadaan diri anak. Orang tua juga harus berusaha menunjukkan empati dan perhatian terhadap kesulitan remaja dan adanya respon yang baik terhadap permasalahan yang dihadapi remaja (Yayah Nurhidayah, 2011)

Membangun komunikasi antara orang tua dengan anak merupakan salah satu kunci dalam upaya perlindungan anak. Komunikasi yang dimaksud adalah memberikan nasehat atau anjuran kepada anak mengenai hal-hal yang menurut orang tua harus didengarkan, diketahui, dan ditaati. Pada akhirnya, anak pun mendapatkan bekal pengetahuan yang dapat menjadi benteng perlindungan dari pengaruh lingkungan yang dapat menjerumuskan mereka (Rozi F, 2015). Penelitian yang dilakukan oleh Sieving et al. (2002) mengatakan bahwa protektor yang mempengaruhi perilaku seksual berisiko pada remaja adalah individu, keluarga, teman sebaya, lingkungan sekolah dan komunitas/ lingkungan sekitar. Komunikasi orang tua merupakan salah satu faktor protektif terhadap perilaku seksual remaja yang berisiko.

Dalam penelitian ini pada saat melakukan FGD, berdasarkan observasi dari psikolog bahwa pernyataan mengenai pentingnya peranan komunikasi orang dan anak terhadap perilaku seksual remaja diketahui bahwa sebagian besar para orangtua memahami bahwa komunikasi secara 
terbuka dengan anak remaja memang diperlukan agar para orangtua dapat memahami perkembangan anak remajanya. Namun komunikasi secara terbuka tentang seksual masih belum cukup terbuka. Terlihat dari orangtua (ibu) yang langsung memberi ultimatum untuk "putus" pada anak remajanya saat mengetahui anak remajanya menjalin hubungan dengan lawan jenis. Pendapat partisipan mengenai jika anaknya mengaku memiliki teman dekat:

"saya seorang ibu, dulu saya pernah muda, tapi kalau anak saya punya pacar, ya....saya larang..saya surub putus saja" (Partisipan FGD).

"saya ga pernab tau apakah anak saya punya pacar apa ga, tapi keliatannya sib biasa aja kalau dirumah, ya mudah-mudaban bener gitu....” (Partisipan FGD)

“kalau saya perhatikan anak-anak sekarang memang beda seperti jaman dulu, kalau saya suka menanyakan main sama siapa saja, ada masalab ga dengan temannya, paling itu aja...."(Partisipan FGD)

"anak pacaran harus langsung potong, orang tua langsung melarang anak untuk pacaran” (Partisipan FGD)

Ketika ditanya kepada orangtua tentang pubertas, orangtua tidak mengetahui kapan pertama kali anaknya mengalami pubertas dan belum tahu bagaimana caranya mengkomunikasikan tentang awal pubertas pada anak. Pendapat partisipan sebagai berikut:

"kalau saya liat pada perubahan suara anak, karena anak saya laki-laki, ya...berarti sudah akil baliq....ya udah gitu aja...” (Partisipan FGD) "aduh...gimana ya, terus terang saya ga ingat kapan anak saya mulai haid, tapi anak saya pernab menanyakan cara menggunakan pembalut, ya segitu aja..." (Partisipan FGD) "kan disekolah sudab diajarkan kali ya.....semoga aja anak.2 pada pabam...." (Partisipan FGD)

Seberapa sering orang tua berbicara tentang risiko penyakit seksual menular jika melakukan hubungan seks sewaktu pacaran? Pendapat partisipan sebagai berikut: "saya sendiri ga pernah ngobrol tentang itu ......." (Partisipan FGD) "saya rasa di sekolah mungkin meraka pernah dapat pelajaran tentang itu" (Partisipan FGD) "sekarang kan udah canggih bu, sudah ada internet...” (Partisipan FGD)

Komunikasi tentang seksualitas lebih dipahami oleh orangtua yang memiliki latar belakang pendidikan Agama Islam (Guru Agama). Pemahaman tentang pubertas diberikan secara terbuka saat anak remajanya sebelum memasuki masa pubertas sehingga anaknya bercerita saat 
benar-benar mengalaminya. Bagaimana penjelasan tentang alat alat reproduksi remaja, partisipan berpendapat:

"saya lebih menekankan anak saya nilainilai agama agar tau mana yang dilarang oleb agama mana yang boleh....." (Partisipan FGD )

"saya rasa anak sudab tau kali ya....karena mungkin dapat informasi dari televisi atau hp mereka...." (Partisipan FGD )

"aduh.....sepertinya agak tabu kalau dijelaskan seperti itu...." (Partisipan FGD )

"seharusnya pihak sekolah juga bisa bertanggung jawab terhadap hal ini..." (Partisipan FGD )

Pendapat partisipan pada saat dilakukan FGD adalah beberapa orangtua cenderung lebih banyak komunikasi satu arah saat membicarakan tentang seksualitas pada anak remajanya (kemungkinan juga untuk hal lainnya). Belum terlihat bahwa mereka juga "mendengarkan" anak remajanya, komunikasi dirumah kurang baik, tidak terbuka, dan orangtua tidak mengetahui solusi jika anak menanyakan tentang kesehatan reproduksi serta dianggap tabu, orangtua melarang keras anak pacaran tanpa mendiskusikan terlebih dahulu, orangtua merasa khawatir sekali terhadap perilaku seksual remaja dikarenakan faktor lingkungan lebih dominan mempengaruhi perilaku anak misalnya adanya internet, tayangan televisi, kadang orang tua lupa anak harus diarahkan ke hal positif yang harus dilakukan apalagi anak SMA sudah matang secara biologis, komunikasikan apa bahayanya hubungan seksual bebas, harus bisa mengendalikan diri sehingga tidak terjerumus. Partisipan juga berpendapat bahwa hal ini merupakan tanggungjawab sekolah.

Pada kegiatan penyuluhan, partisipan belum terlihat antusias tentang topik yang diberikan dan masih melihat ini adalah hal yang tabu dan terlalu vulgar untuk dijelaskan kepada remaja. Pada saat dilakukan postest untuk FGD pendapat partisipan mengenai peran komunikasi orangtua terhadap perilaku seksual remaja diketahui bahwa orangtua terlihat memahami bahwa komunikasi secara terbuka dengan anak remaja memang diperlukan agar para orangtua dapat memahami perkembangan anak remajanya. Beberapa orangtua sebelumnya cenderung lebih banyak komunikasi satu arah saat membicarakan tentang seksualitas pada anak remajanya (kemungkinan juga untuk hal lainnya). Belum terlihat bahwa mereka juga “mendengarkan" anak remajanya, namun sekarang orangtua sudah mulai membuka 
interaksi dengan remaja sambil terus mempelajari tentang perilaku seksual remaja salah satunya dengan modul yang disiapkan oleh peneliti.

Partisipan memiliki kesadaran akan tanggung jawab mereka untuk menjaga anak agar terhindar dari perilaku seksual bebas, walaupun sebagian partisipan berpendapat bahwa remaja memiliki peluang terhadap masalah tersebut karena faktor lingkungan. Akan tetapi,sebagian besar partisipan berpendapat bahwa pihak yang bertanggungjawab penuh terhadap perlindungan anak dari perilaku seksual remaja adalah orang tua. Pertisipan menganggap lingkungan eksternal, seperti tetangga, guru di sekolah, dan sebagainya, juga memiliki tanggung jawab untuk menjaga remaja.

Hal yang sama juga pada kelompok penyuluhan, partisipan menunjukkan sikap terbuka dengan memberikan informasi, walaupun masih ada sebagian kecil $(30 \%)$ orangtua masih merasa tabu untuk menjelaskan tentang perilaku seksual remaja dikarenakan salah satunya adalah faktor budaya setempat yang dianggap terlalu dini membahas hal tersebut.Menurut Rozi F (2015) bahwa tanggung jawab orang tua yang dimaksud adalah memberikan bekal pendidikan agama dan informasi sebagai upaya pencegahan. Orang tua mempunyai peranan penting dalam perkembangan anak, akan tetapi, waktu yang digunakan orang tua untuk berinteraksi untuk mengkomunikasikan dengan anak cenderung berkurang, walaupun sebenarnya anak masih sangat membutuhkan orang tua.

\section{KESIMPULAN}

Berdasarkan hasil penelitian maka dapat disimpulkan sebagai berikut bahwa terdapat peningkatan peranan komunikasi orangtua pada kedua kelompok, namun kelompok perlakuan peningkatannya lebih tinggi dibandingkan kelompok kontrol. Berdasarkan kesimpulan tersebut maka disarankan bagi Diharapkan penentu kebijakan di SMAN 3 Kota Cirebon dapat mengikutsertakan orang tua terutama dalam hal mempersiapkan remaja menjadi generasi yang sehat, berperilaku sesuai dengan norma agama pada setiap kegiatan yang diadakan disekolah seperti rapat orangtua.

\section{REFERENSI}

Amanda,K.(2014). Efektifitas Penkes Metode Focus Group Discussion Dan Media Visual Terbadap Pengetahuan Dan Sikap Warga Binaan Pemasyarakatan 
Tentang Infeksi Menular Seksual Di

Lapas Kelas IIa Wanita

Bandung.Universitas Padjajaaran

Fakultas keperawatan Bandung

Amran, A. A. (2010). Komunikasi Antar

Pribadi Orangtua dan Anak dalam

Menanamkan Pengetahuan

Bahasa Daerah (Studi Deskriptif

pada Orangtua dan Anak di

Lingkungan III Kelurahan

Tembung-Kecamatan Medan

Tembung).

repository.usu.ac.id/ bitstream/123456

789/18039/1/Appendix.pdf

Fajarwati,M.(2011).Pola Komunikasi Orang

Tua Dengan Anak Remaja Dalam

Berinternet Sehat Di Surabaya (Studi

Kualitatif Tentang Pola Komunikasi

Orang Tua dengan Anak Remaja

dalam Berinternet Sehat di Surabaya).

Fauzy, ZF \& Indrijati,H.(2014). Pola

Pacaran Faktor Penyebab Tingginya

Risiko Seks Pranikah.

Ginting, MDR, (2014). Efektivitas Focus

Group Discussion Terbadap

Peningkatan Smoking Self Efficacy

Pada Kelompok Pria Dewasa Awal

Kategori Perokok Sedang. Program

Pendidikan Magister Psikologi

Profesi Fakultas Psikologi

Universitas Sumatera Utara

Jaccard, J., Dodge, T., \& Dittus, P. (2002).

Parent-adolescent

Communication
About Sex and Birth Control: A Conceptual Framework. In New Directions For Child and Adolescent Development (Vol. 97, pp. 1-41). California: (C) Wiley Periodicals, Inc.

Munawaroh,F. (2012) Konsep Diri, Intensitas Komunikasi Orang Tua-Anak, dan Kecenderungan Perilaku Seks Pranikah. Persona, Jurnal Psikologi Indonesia September 2012, Vol. 1, No. 2, hal 105-113

Nurhidayah,Y. (2011). Pengaruh Komunikasi Orang Tua Tentang Pengetahuan Kesehatan Reproduksi dan Penanaman NilaiNilai Religiusitas Terhadap Prilaku Seksual Remaja. Holistik Vol 12 Nomor 02, Desember 2011/1433 $\mathrm{H}$

Prihartanti, Z dkk. (2013). Pengaruh Penyuluban Kesehatan Reproduksi terhadap pengetabuan tentang peran orangtua dalam memberikan pendidikan seks pada remaja di $\mathrm{R} W 3$ Sorosutan umbulharjo Yogyakarta.

Putra,NFP. (2013).Peranan Komunikasi Interpersonal Orang Tua Dan Anak Dalam Mencegah Perilaku Seks Pranikah Di SMA Negeri 3 Samarinda Kelas XII.Ejournal Ilmu Komunikasi, Volume 1, Nomor 3, 2013 35-53 
Ramos, V. G., \& Bouris, A. (2008). Parent adolescent communication about sex in latino families: A guide for practitioners. Washington: The National Campaign.org Teen

Pregnancy.org Stay Teen.org.

Rozi F. (2015).Meningkatkan Peran Orangtua Siswa dalam Pencegahan Penyalahgunaan Narkoba melalui Penyuluhan Narkoba Berdasarkan Assmen Kebutuhan Penyuluhan. Universitas Muhammadiyah Prof. DR. HAMKA. Jurnal Ilmiah Penelitian Psikologi: Kajian Empiris \&Non-Empiris Vol. 1, No. 1, 2015. Hal. 17-32

Salisa,A. (2010) Perilaku Seks Pranikah Di Kalangan Remaja (Studi Deskriptif Kualitatif Tentang Perilaku Seks Pranikah Di Kalangan Remaja Kota Surakarta). Skripsi Jurusan Sosiologi Fakultas Ilmu Sosial Dan Ilmu Politik Universitas Sebelas Maret Surakarta.

Sieving, R. E., Jennifer A, R., Robert, O., \& Blum, W. (2002). Adolescent Sexual Behavior and Sexual Health. Pediatrics in Review, 23(12), 407-15.

Soejati, SZ, (2010). Perilaku Seks Dikalangan Remaja dan
Permasalahannya.Media Litbang

Kesehatan vol. XI Nomor 1 Tahun 2001

Suryoputro1, dkk. (2006). Faktor-Faktor Yang Mempengaruhi Perilaku Seksual Remaja Di Jawa Tengah: Implikasinya Terhadap Kebijakan Dan Layanan Kesehatan Seksual Dan Reproduksi. Makara, Kesehatan, Vol. 10, No. 1, Juni 2006: $29-40$

Suzuki, K., Motoshahi, Y., \& Kaneko, Y. (2006). Factors Associated With The Reproductive Health Risk Behavior of High School Students In The Republic of The Marshall Islands. J Sch Health, 76(4), 138144. 